\title{
Canada. Une efficacité à confirmer le cas de
} l'Ontario

Études de cas

Marie J. Myers

\section{(Q) OpenEdition}

\section{Journals}

Édition électronique

URL : https://journals.openedition.org/ries/1289

DOI : 10.4000/ries. 1289

ISSN : 2261-4265

\section{Éditeur}

France Education international

Édition imprimée

Date de publication : 1 décembre 2005

Pagination : 68-70

ISSN : $1254-4590$

Référence électronique

Marie J. Myers, "Canada. Une efficacité à confirmer le cas de l'Ontario », Revue internationale d'éducation de Sèvres [En ligne], 40 | décembre 2005, mis en ligne le 17 novembre 2011, consulté le 06 juillet 2021. URL : http://journals.openedition.org/ries/1289; DOI : https://doi.org/10.4000/ries.1289

Ce document a été généré automatiquement le 6 juillet 2021

() Tous droits réservés 


\section{Canada. Une efficacité à confirmer le cas de l'Ontario}

Études de cas

Marie J. Myers

1 Dans le système provincial du Canada, les établissements scolaires, groupés par commissions scolaires régionales, jouissent d'une grande autonomie. Les écoles privées et les nouvelles « écoles de la Charte ", sous l'égide du ministère de l'Éducation pour les programmes, sont très indépendantes et populaires. L'autonomie engendre une émulation qui peut augmenter l'efficacité pédagogique et la réussite des élèves mais crée aussi de nouveaux problèmes.

\section{Vers plus d'ouverture et d'autonomie}

2 Les directives du ministère sont précises tout en permettant une adaptation au contexte, ce qui va dans le sens d'une école plus autonome. Dans l'ensemble, la variété des apprentissages individuels est respectée. La diversification des activités se fait selon la théorie des « intelligences multiples » (Gardner, 1993). On s'interroge sur les besoins d'apprentissage ; on enseigne la prise en compte de stratégies individuelles. Le contrôle des connaissances comprend une évaluation formative et sommative ainsi que des grilles d'évaluation aux critères gradués et précis permettant la négociation et même l'auto-évaluation des élèves.

3 L'élève doit prendre en charge son apprentissage. Il s'agit pour lui de comprendre les attentes relatives à chaque critère et le nombre de points donné. Les enseignants développent des contrats individualisés pour chacun. Mais la rigidité de certains enseignants empêche d'appliquer cette démarche partout. Parfois, ils attendent une conduite identique de tous les élèves de la classe; parfois au contraire, trop de contraintes sont abolies (un directeur de commission scolaire a même prôné l'évaluation des travaux sans tenir compte des fautes d'orthographe). 
4 Le test d'alphabétisation imposé pour améliorer le niveau de maitrise de la première langue (L1), qui ne respecte pas les différences individuelles, va à l'encontre de la nouvelle tendance vers l'ouverture et l'autonomie.

Des descriptions détaillées régissent l'enseignement de chaque matière à chaque niveau tout en permettant l'adaptation. Le guide des enseignants contient des exemples de travaux d'élèves représentatifs des niveaux à atteindre, du moins élevé au plus élevé, ainsi qu'une évaluation détaillée de ces travaux. Ces descriptions de cours, la philosophie adoptée et les contenus sont louables. L'ajout de cours appliqués et la possibilité de centrer un cours sur les besoins locaux sont autant d'efforts pour motiver des élèves issus de contextes différents, donnant aussi plus d'autonomie aux écoles.

6 On attend une note moyenne de $79 \%$ pour la plupart des élèves et les grilles d'évaluation visent cet objectif.

\section{L'émergence des difficultés}

7 Avec l'autonomie de l'école, les responsabilités des enseignants augmentent. Les locuteurs de langue étrangère (L2) sont inclus dans les cours L1 et les cours de langue visent le développement de la littéracie pour tous, avec peu d'aide aux nouveaux Canadiens. Les enfants ayant des difficultés d'apprentissage sont intégrés dans les classes normales et tous les enseignants doivent se recycler pour comprendre tous les besoins.

8 Les cours appliqués préparant à l'emploi, bien qu'excellents, n'ont pas le succès escompté car le choix est rarement établi sur un critère professionnel. On visait à développer chez des élèves doués des aptitudes de cadres techniques et d'artisans spécialisés mais seuls les plus faibles se retrouvent dans ces cours.

9 De nombreux échecs ont été recensés au test d'alphabétisation (certains dus à des items inadéquats). La régionalisation, qui avait pour objectif de répondre à des besoins divers, a des effets négatifs sur les citadins et les nouveaux Canadiens comme le montrent des questions relatives à la pêche traditionnelle. Enfin, le remplacement d'items afin d'augmenter le taux de réussite, résultat de la pression que font peser les tests internationaux, pose problème.

Les taux de réussite des "écoles de la Charte ", les plus autonomes, sont élevés, leur population d'étudiants étant sélectionnée et leurs enseignants triés sur le volet (au Canada, le poste dépend de l'offre et de la demande et l'enseignant n'est pas fonctionnaire).

11 L'accès à l'université est déterminé par les notes obtenues au secondaire et non par un examen. Certaines écoles plus autonomes sont perçues comme la garantie de meilleures notes. Toutefois, le niveau des élèves varie grandement selon le contexte socioculturel et familial.

12 Les exemples fournis pour le contrôle des connaissances en classe laissent une grande marge d'adaptation, les normes variant grandement selon l'appréhension des directives par l'enseignant et son degré de formation.

13 Le programme actuel ne favorise pas de vraies passerelles pour les immigrés qui restent toujours en arrière. 


\section{BIBLIOGRAPHIE}

ELLIS R. (1990): Instructed Second Language Acquisition, Cambridge, U.K., Basil Blackwell.

GARDNER H. (1993): Multiple Intelligences, New York, Basic Books.

http://www.edu.gov.on.ca/fre/relsites/othernet.html

http://www.curriculum.org/occ/lecle.shtml

http://www.lecle.com/

INDEX

Index géographique : Canada, Ontario 
AUTEUR

MARIE J. MYERS

Professeur, Queen's University, Ontario, Canada. 